Journal of Mathematics and Statistics 8 (1): 64-71, 2012

ISSN 1549-3644

(C) 2012 Science Publications

\title{
Modeling of Engineering Student Satisfaction
}

\author{
${ }^{1}$ Zainol Mustafa, ${ }^{2}$ Norbayani Basri, ${ }^{1}$ Norkisme Zainal Abidin, ${ }^{1}$ Nur Riza Mohd Suradi, \\ ${ }^{1}$ Zalina Mohd Ali, ${ }^{1}$ Faridatul Azna Ahmad Shahabudin and ${ }^{3}$ Mohd Rashid Ab Hamid \\ ${ }^{1}$ School of Mathematical Sciences, Faculty of Science and Technology \\ University Kebangsaan Malaysia, 43600 UKM Bangi, Selangor D.E. \\ ${ }^{2}$ Ministry of Education, Malaysia \\ ${ }^{3}$ Faculty of Industrial Sciences and Technology, \\ University Malaysia Pahang, Lebuhraya Tun Razak, 26300 Kuantan, Pahang D.M.
}

\begin{abstract}
Problem statement: The purpose of this study is first; to identify the antecedents to student satisfaction and the relationship between student satisfaction and promotion. Second; to develop a suitable student satisfaction model considering the antecedents of student satisfaction with student satisfaction and promotion for students of engineering in universities in Malaysia. A total of 500 engineering students from University Kebangsaan Malaysia (UKM), University Putra Malaysia (UPM), University Islam Antarabangsa Malaysia (UIAM), University Malaya (UM) and University Tenaga Nasional (UNITEN) were involved as respondents in this research. Approach: To examine these relationships, a model from past study on student satisfaction of Applied Sciences students in Austria was referred. Based on this model, a suitable model measuring student satisfaction of engineering students in Malaysia is constructed. Structural equation modeling is used as its capability in testing the combination of relationship between service performance, university performance, relationship, university standing, student satisfaction and promotion in higher education simultaneously. Results: Suitable model which is able to explain the factors linked to student satisfaction in engineering education is established. Conclusion: This study finds that the antecedent factors have a direct effect on student satisfaction and also student satisfaction has a significant effect on promotion.
\end{abstract}

Key words: Student satisfaction, engineering education, structural equation modeling, university standing, service performance, engineering education, higher education

\section{INRODUCTION}

The world has become a global environment which forces higher learning institutions to reposition internationally. Additional resources therefore are needed for the institutions to face long term challenges in improving or maintaining existing standards, increasing students' access and facilities as well as strengthening market connections and competition globally. It is understood that competition increases not only in getting new students to enrol but also in getting financial support. Higher learning institutions should give the marketing factor more attention in achieving the desirable number of students' enrolment. This is merely because the students can be considered as customers and they are the determining factor to the survival of a higher learning institution. In general, the importance of marketing has become more accepted in the Higher Education environment.
Customer satisfaction is achieved when a customer is satisfied with a product or service that meets their requirements, needs or expectations. Satisfaction can be viewed as an outcome of a consumption activity or experience (Parker and Mathews, 2001) and many researches have been conducted recently especially at Higher Education Institution at different issue (Khozaei et al., 2010; Najib et al., 2011). Customer satisfaction also has an effect on the image of an organisation. There is an indirect relationship between customer satisfaction and customer loyalty through image (Bloemer and Ruyter, 1998). Satisfied and loyal customers can be very good and influential agents of promotion. They have the potential of being persuasive thus promoting the service they received, for instance, through wordof-mouth testimonials to neighbours, friends and relatives or even strangers. Therefore, customer satisfaction should be given proper attention by

Corresponding Author: Zainol Mustafa, School of Mathematical Sciences, Faculty of Science and Technology, University Kebangsaan Malaysia, 43600 UKM Bangi, Selangor D.E. Malaysia Tel: 03-89213597 Fax: 03-89254519 
service providers since it reflects the quality of service provided, thus, affects the promotion of the service and helps improve the standing of the organisation in the market.

Student satisfaction should be better managed since it can be a key factor in achieving promotional and sales objectives. Higher learning institutions need to identify the antecedents which will increase student satisfaction as this can help the institutions in its marketing. Therefore, a coherent student satisfaction model is needed to help higher learning institutions manage the student satisfaction with respect to the product, organisation, relationship as well as marketing. Focusing on student satisfaction not only enables universities to reorganise accordingly but also gives universities the opportunity to develop a system for continuous monitoring in meeting or exceeding the students' needs effectively (Elliot and Shin, 2002). Students as part of customer and stakeholder in university should be treated fairly with values (Hamid et al., 2010a; Abdullah et al., 2011). Therefore, the need to focus on the student satisfaction is important in developing a culture of continuous quality improvement (Aldrige and Rowley, 1998). Jurkowitsch et al. (2006) views that there is a need for a student satisfaction model due to the following reasons. First, students are special customers in a specific service environment. Second, they are a part of the development of a product. Third, student satisfaction changes over time and fourth, they are the ones transporting the 'picture' of a university worldwide. To succeed, a university needs to have various strategies in promoting the product and service offered. Jurkowitsch et al. (2006) suggested that antecedents to student satisfaction are service performance, university performance, relationships and university standing. These four dimensions are modelled as the antecedents to the key mediating construct that is overall student satisfaction. Promotion, as a dimension is modelled as a potential outcome of overall student satisfaction. Satisfaction or dissatisfaction should increase the possibilty of students reacting in some way. The reaction may include giving word-of-mouth testimonials or warnings, changing of brand attitudes or complaining and complementing (Woodruff et al., 1983).

The purpose of this study is to identify the antecedents to student satisfaction and the relationship between student satisfaction and promotion. Then, to develop a suitable student satisfaction model connecting the antecedents of student satisfaction with student satisfaction and promotion for students of engineering in universities in Malaysia. This model is based on the pre- conceptual model by Jurkowitsch et al. (2006) for the research conducted on students taking diploma in Applied Sciences in Austria. There are five categories of approach used by previous researchers on students' perception towards the quality of educational services. They are, academic service, administration service, the gap between students' expectations and experiences, physical aspects and institution reputation.

Academic service includes courses offered, quality of lecturers, entry requirements, conduct of lectures and appearance of academic staff. Administration service includes the helpfulness of staff, positive attitudes towards the students and the effectiveness and efficiency of the staff. The gap between students' expectations and experiences covers the difference between their expectation prior entering the institution and the real experience they have afterwards. Physical aspects include facilities such as access to information, equipments for practical work, laboratories, accommodation and leisure facilities. Institution reputation is also a crucial factor. This relates to the credibility and reputation scale for institutions and academic reputation scale by Joseph and Joseph (1997). It is hoped that this study will help higher learning institutions to focus all efforts towards improving those antecedent factors leading to student satisfaction, thus improving the level of student satisfaction with the services provided.

Service quality: Improving customer service quality can help organisations to succeed in global market competition although the determining factor to service quality may vary from one industry to another. In general, service quality is no more and no less than to what extent does the service provider exceeds or fail in achieving the customer's satisfaction (Babakus and Boller 1992; Parasuraman et al., 1988). Parasuraman et al. (1988) defined customer satisfaction as the fulfilment or the need of a customer. Based on this definition, customer expectation, once exceeded by the service provider, will result in customer satisfaction, thus leading to a positive result in customer evaluation on the quality of service provided.

Higher Education Institution (HEI) can be regarded as having the characteristics of a service industry. In order to understand what service quality means, it is important to understand the characteristics that a service has. These characteristics make measuring service quality harder than measuring the quality of a product. Generally, service quality is a critical factor in profit generation and to the success of an organisation. Venetis and Ghauri (2004) explained that there are two contributions of service quality in profit generation. 
First, regardless of the type of services provided, service quality is able to attract new customers thus contributing to bigger market share. Second, service quality increases the possibility of the customer acquiring the service again, acquiring it more or often, acquiring other services from the provider, making the customer less aware of the price or tell other potential customers about the positive experience they have with the service. Therefore, higher education institutions need to actively monitor and control the quality of service provided by them and commit to the efforts of continuous improvement to survive the ever more challenging competition in getting new quality students to enrol and achieving the targeted profit.

Customer satisfaction and promotion: The customer is an entity that receives a certain service or product from a certain process in a system. The customer can be in the same position as the process, between two processes or at the end of a system. Satisfaction can be viewed as an outcome of a consumption activity or experience (Parker and Mathews, 2001). Customer satisfaction is achieved when a customer is satisfied with a product or service that meets their requirements, needs or expectations. It is usually measured as a final result to a quality of a product or service. Customer satisfaction is also seen as existing in line with the realisation of customer value. It is the final result of all the processes involved in a production of a product or delivery of service. Marketing and promotion involve all aspects of customer's needs, customer's expectation, customer's tendency, customer's attitude and customer's lifestyle. In both theories of marketing and practical experiences, an organisation needs to improve its performance through satisfying the customers so that it retains its position and gain reputation in the market.

Customer satisfaction in education: Student satisfaction is one of the important factors that need to be given serious attention to ensure students loyalty to the university and enrolment of new students. Students are agents of promotions whom universities can depend on in improving its reputation in the market and the image that the public has of the universities in fulfilling customers's satisfaction. If an organisation does not know what the customers want, how can it design programmes to suit and meet the customers' expectation on what they perceive as a satisfying service. Theoretically and practically, education administrators need to understand the main and specific needs of the customers, that is the students, in designing courses and executing programmes. This will help in handling issues and eliminating factors leading to dissatisfaction. In addition, education service providers should focus mainly on specifications, evaluations, monitoring and improvement of customers' perception of service quality. Focusing on student satisfaction not only enables universities to reorganise accordingly but also gives universities the opportunity to develop a system for continuous monitoring in meeting or exceeding the students' needs effectively (Elliot and Shin, 2002). Therefore, the student satisfaction approach is important in developing a culture of continuous quality improvement (Aldrige and Rowley 1998).

Student satisfaction: Elliot and Shin (2002) stated that student satisfaction is a worthy factor to study as it benefits the students. This includes the increase in motivation, lower attrition rates and a greater number of referrals. However, there are a few reasons to be considered when applying the student satisfaction approach in Higher Education (Wiers-Jenssen et al., 2002). This is due to the fact that feelings and emotions are not completely taken into account as the variables in the satisfaction process (Wirtz and Bateson, 1999). Student satisfaction is a complex construct with various antecedents and they are not the same as those in the actual customer satisfaction models, as student satisfaction is a continually changing construct in the Higher Education environment due to repeated interactions (Elliot and Shin, 2002). It is important to understand the factors contributing to student satisfaction in order to grasp the complexity of learning experiences (Jurkowitsch et al., 2006). For many students, the process of learning does not only involve the acquisition of certain skills and theoretical knowledge, but it is also related to personal growth and social development (Wiers-Jenssen et al., 2002).

Student satisfaction model: Jurkowitsch et al. (2006) views that there is a need for a student satisfaction model due to the following reasons. First, students are special customers in a specific service environment. Second, they are part of the development of a product. Third, student satisfaction rate changes over time and fourth, they are the ones transporting the 'picture' of a university worldwide. To succeed, a university needs to have various strategies in promoting the product and service offered. Jurkowitsch et al. (2006) suggested that antecedents to student satisfaction are service performance, university performance, relationships and university standing. These four dimensions are modelled as the antecedents to the key mediating construct that is overall student satisfaction. Promotion, 
as a dimension is modelled as a potential outcome of overall student satisfaction. Satisfaction, whether positive or negative, should increase the possibilty of students reacting in some way. The reaction may include giving word-of-mouth testimonials or warnings, changing of brand attitudes or complaining and complementing (Woodruff et al., 1983). The preconceptual model proposed is shown in Fig. 1.

Research method: Service performance is a key construct in marketing research especially those involving service quality. In the context of Higher Education, service performance includes implicit quality influenced by university professors and specific course content. Wiers-Jenssen et al. (2002) found that the important factors in service performance are teaching and social climate. Higher student satisfaction rate can be achieved when students are provided with a curriculum that meets their needs and expectations especially when it is focused on high quality instructions and opportunities to develop their skills (BCCISO, 2003).

University performance: Universities provide other services beside academic services and these supporting services are important for students to be able to complete their course and as one of the competitive advantages (Hill, 1995). Also, campus environment may be seen as a web of connecting events that influence student satisfaction (Elliot and Shin, 2002). These support services include classroom facilities, source of reference, laboratory facilities, internet access and administration structure.

Relationships: Relationships vary between a student and the university from transactional to highly relational bonds (Garbarino and Johnson, 1999). There are two important factors of student satisfaction regarding relationships; bonding and empathy. Bonding is defined as 'the dimension of relationship that results in two parties acting in a unified manner towards a desired goal' (Yau et al., 2000). Family, lecturers, university personnels, reference groups and social norms may influence the bond between students and university (Garbarino and Johnson, 1999). In the same way, empathy is defined as trying to understand someone's needs and goals (Yau et al., 2000). There are also indicated links between empathy and reciprocity. Reciprocity means that university does not only take but also gives something back in return (Arnett et al., 2003). Conclusively, satisfaction is a result of reciprocity that occurs between students and the university personnels.
University standing: Administrators of successful universities realise that it is important to retain existing students rather than focusing on attracting new ones. One of the reasons is that satisfied students give a competitive edge to a university and can be very useful tools of marketing. Decisions made on which university to choose lies on the university's location, facilities, image, curriculum, quality of students among others (Washburn and Petroshius, 2004). Prestige, image, reputation and positioning are the elements that need to be displayed in the promotion of a university.

\section{MATERIALS AND METHODS}

Population and sample: A total of 500 engineering students from Universiti Kebangsaan Malaysia (UKM), Universiti Putra Malaysia (UPM), Universiti Islam Antarabangsa Malaysia (UIAM), Universiti Malaya (UM) dan Universiti Tenaga Nasional (UNITEN) were the respondents in this research. The data used is a secondary data obtained from a previous research on student satisfaction.

Research method: Structural Equation Modelling (SEM) is the method used to analyse the data in this study. It is a statistical method with a confirmatory approach to analyse a theory on a phenomenon (Byrne, 2001). Variables in a hyphothesized model can be tested statistically and concurrently. The proposed model consists of observed variables and latent variables. Latent variables are also known as factors or constructs and observed variables are also known as indicators. Indicators are the items in the questionnaire used to observe the constructs. A SEM model is divided into two submodels; the measurement model and the structural model. The measurement model is first developed and evaluated separately from the full structural equation model that simultaneously models measurement and structural relations. The measurement model, in conjunction with the structural model, makes a comprehensive confirmatory assessment of construct validity possible. It defines the relations between indicators and construct. Readers are referred to Hamid et al. (2011a; 2011b) for examples of CFA use. Next, the structural model defines the relations between constructs. The full structural equation model is a model that has all of the hyphothesized relations for both measurement and structural models. as shown in Fig. 1. 


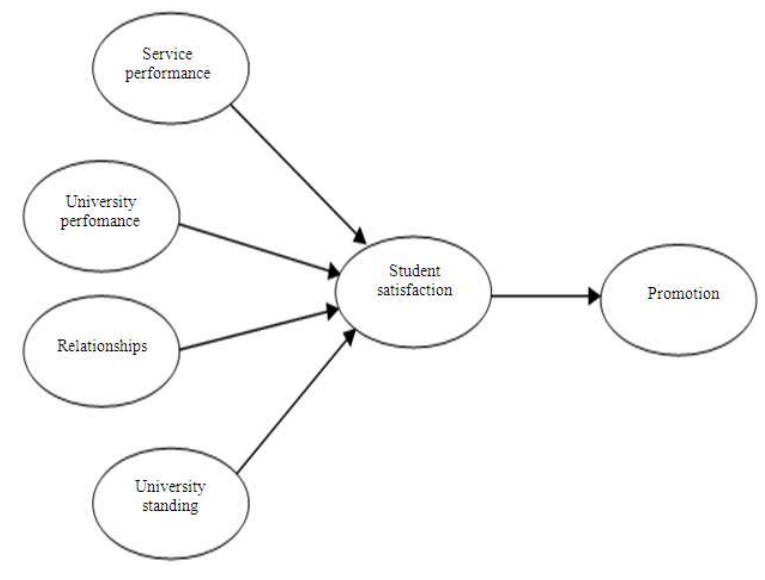

Fig. 1: Proposed full structural equation model for engineering students' satisfaction model in Malaysia (adopted and adapted from Jurkowitsch et al. (2006) pre-conceptual model)

Table 1: Cronbach's alpha

\begin{tabular}{lc}
\hline Variable & Alpha value \\
\hline Antecedents of students' satisfaction: & \\
-Service Performance & 0.948 \\
-University performance & 0.875 \\
- University Standing & 0.887 \\
Relationships & 0.819 \\
Student Satisfaction & 0.905 \\
Promotion & 0.828 \\
\hline
\end{tabular}

Data analysis: Extreme data elimination: The data in this study is analysed using Statistical Package for Social Sciences (SPSS) version 16 and AMOS version 5. However, the first step is applying the Mahalanobis distance to eliminate any existing outliers in the data. Mahalanobis Distance is used to eliminate any extreme data from the original data of 500. A total of 38 items were chosen to represent the six variables in the proposed model. The Mahalanobis Distance for each respondent is obtained using SPSS. The minimum distance of 2.145 and the maximum distance of 177.015 were obtained from the output. With 38 as the degree of freedom and confidence level of $99.99 \%$ ( $p=0.001)$, 70.71 was obtained from the Chi-Square table. Data exceeds this critical value is then eliminated. This study is left with 462 respondents from the initial 500 respondents after the elimination of 38 outliers. Analysis on demographic factor is then done using the data from the 462 respondents left.

Realibilty analysis: Realibility analysis is done on all the factors; service performance, university performance, university standing, student satisfaction and promotion. Cronbach's Alpha obtained for all six factors are within the range of 0.828 dan 0.948 (Table 1). According to Hair and Anderson (2010), Cronbach's Alpha exceeding 0.70 shows an item being reliable. Hence, with all the items having an alpha exceeding 0.70 , it shows that all the data for this study are reliable.

Factor Analysis: Factor analysis is then carried out on the items for all six variables. This was to check for confirmation on the placing of the items chosen for each variable. The objective of the factor analysis is to make sure that the data is consistent with the structure in place. In other words, it is is to confirm whether the relationship based on theory that items have with a particular variable really exist. The exploratory factor analysis is done to check on the four antecedent factors to student satisfaction. Then, two measurement models are developed. One model shows the relation of the five antecedents to student satisfaction and another model shows the relation between student satisfaction and promotion. Each model is then tested with AMOS using the data from 462 respondents left and the fitness index is observed. Items with regression weight less than 0.4 will be taken out from the model. Then the model is tested again and the fitness index observed. After the model fit index is achieved for both models, the proposed SEM model is then developed using both measurement models and is analysed using AMOS.

Findings: Out of 462 respondents, $67.1 \%$ of them were male and the rest $(32.9 \%)$ were female. In terms of race, $73.4 \%$ of them were Malays, followed by $24.9 \%$ Chinese, $0.9 \%$ Indians and $0.9 \%$ from others. Majority of the respondents $(99.8 \%)$ were in the Bachelor program and only $0.2 \%$ respondents were in the Masters program. In terms of the courses enrolled, $27.1 \%$ of the respondents were from Mechanical Engineering, $20.8 \%$ from Civil Engineering, $21.9 \%$ from Electrical Engineering, $13.0 \%$ from Chemical Engineering, $12.6 \%$ from Electronic Engineering and $4.8 \%$ were from other engineering courses.

Factor Analysis: As a result, it is found that three components are obtained for the antecedents of student satisfaction. It is found that items for Service Performance and University Standing remain in their respective factors but items for University Performance and Relationships are grouped together under one component. This common factor is then renamed as factor of University Performance as there are elements of relationships within the factor of University Performance such as in the structure of administration where relationships between the administration, staff and lecturers do exist. 


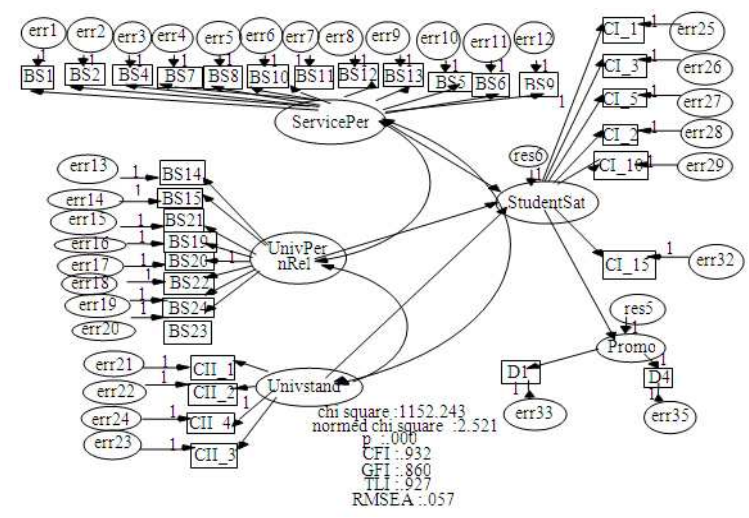

Fig. 2: SEM Model II

Table 2: Fit Indices for the hypothesized model of engineering students' satisfaction model in Malaysia

\begin{tabular}{lll}
\hline Measurement & Index Model I & Model II \\
\hline $\mathrm{X}^{2}$ & 1491.890 & 1152.243 \\
$\mathrm{df}$ & 587 & 457 \\
$p$-value & 0.000 & 0.000 \\
TLI & 0.914 & 0.927 \\
NFI & 0.875 & 0.893 \\
GFI & 0.840 & 0.860 \\
RMSEA & 0.058 & 0.057 \\
AIC & 1649.890 & 1294.243 \\
\hline
\end{tabular}

Table 3: Items with $<0.500$ squared multiple correlation (SMC)

\begin{tabular}{ll}
\hline Item & SMC \\
\hline CI_11 & 0.454 \\
CI_13 & 0.411 \\
D2 & 0.305 \\
D3 & 0.446 \\
\hline
\end{tabular}

Model analysis: As shown in Fig. 1, the model developed based on the pre-conceptual model by Jurkowitsch et al. (2006) for their research on Applied Sciences students in Austria, showing the relationships between the antecedents of student satisfaction, with student satisfaction and promotion. Nevertheless, this model is modified based on the result of the factor analysis by combining the factors of University Performance and Relationships into one common approach, this model is suitable for the data obtained in this study due to the small value of RMSEA that is 0.058 . Other fit indice i.e. the TLI value is 0.914 which is more than 0.9 while the NFI value is 0.875 and the GFI value is 0.840 and are very close to 0.9 . Thus, this model is acceptable (Table 2).

In addition, the regression weight for items are observed. It is observed that the reading for item D2 is relatively low compared to other items for Promotion and the squared multiple correlation value of 0.305 for that item is also less than 0.400 . This shows that item
D2 contributes as much as $69.5 \%$ in error of variance. Thus, item D2 may be eliminated to get a better fit of the model. With reference to the squared multiple correlation (SMC) value for all items, it is found that the value for items CI_11, CI_13 and D3 (0.454, 0.411 and 0.446 respectively) are below 0.5 as shown in Table 3. This means, they contribute to more than $50 \%$ in error of variance for the model. Hence, these items may be eliminated as well.

After items CI_11, CI_13, D2 and D3 are eliminated, there is an increase in the fit indices for the model (Table 2). Figure 2 shows the respecified model (Model II) which is the alteration to Model I. By considering the fit indices, it is clear that Model II is more suitable to show the relationships between factors that lead to student satisfaction and the relationship between student satisfaction and promotion for the data.

For a model that fits perfectly, the Chi-Square value has to be small with a p-value of more than 0.05 . Looking at both Model I and Model II in this study, the $\mathrm{p}$-value obtained is 0.000 . However, the p-value for the Chi-Square tests is highly dependable on sample size and to get the desired p-value is hard where a large sample size is involved. Thus, the Chi-Square test for model fit is not practical (Cheung and Rensvold, 2002).

As mentioned earlier, Table 2 shows the indexes for both Model I and Model II. It is clear that Model II has a higher fitness value having a TLI of 0.927 , a GFI of 0.860 and a NFI very close to 0.900 . The RMSEA value of Model II is slightly smaller than of Model I making it a better model for the data. Furthermore, the AIC value for Model II is also smaller than of Model I. This shows that Model II is more suitable to show the relationships between antecedents, student satisfaction and promotion for the engineering students in the five universities. Next, the regression weight between variables in the model is analysed. The regression weight shows the significance of the relationships. Table 4 shows the regression weight of all the relations for Model II. There are direct influences on student satisfaction from the service performance factor, the university performance factor and the university standing factor. The biggest influence comes from university standing with the regression weight of 0.429 . This shows that added value has a strong effect on the perception a student has of a university. Service performance, with a regression weight of 0.338 , too has an important effect on student satisfaction. This shows that the perception and experience students have regarding course delivery and classroom experience may lead to students being satisfied. 
Table 4: Regression weight

\begin{tabular}{lll}
\hline Relations & Weight & \\
\hline Student & & \\
Satisfaction & <---Service Performance & 0.338 \\
Student & & \\
Satisfaction & <---University Performance & 0.137 \\
Student & & \\
Satisfaction & <---University Standing & 0.429 \\
Promotion & <---Student Satisfaction & 0.289 \\
\hline
\end{tabular}

University standing also plays an important part with a regression weight 0.137 . The relationships between university personnels and the students, as well as the support systems that the university has in enabling students to complete their studies had a very significant effects on student satisfaction. Table 4 also shows that student satisfaction had an effect on promotion, with a regression weight of 0.289 . Although the value is relatively small, the effect that student satisfaction had on the promotion of a university cannot be ignored.

\section{RESULTS AND DISCUSSION}

This study aims to identify the relationships between four antecedents of student satisfaction; service performance, university performance, university standing and relationships with student satisfaction and between student satisfaction and promotion of the engineering students in five universities in Malaysia. It developed a student satisfaction model having those relationships, based on the pre-conceptual model by Jurkowitsch et al. (2006). From this study, it is found that there are significant relationships between the four antecedents with student satisfaction and between student satisfaction and promotion.

This can be seen from the results of SEM showing the relationships between the variables. However, the antecedent factor of university performance and relationships are grouped together as one component factor which this study referred to as university performance. This is due to the overlapping elements between university performance and relationships. From the explanation on the two antecedent factors, it is concluded that relationships refers to relationships between students and the staff, administration personnels, lecturers and classmates which are all included in the explanation on university performance regarding support system and personnels involved for students to complete their studies.

This study also shows a significant effect that student satisfaction has on promotion. The satisfaction that students get in acquiring the services offered and the learning experience they have in the university, has a positive impact on their perception of the university.
Satisfied students can be potential agents of promotion once they move into post graduate and the real world life. This can help the university in getting new students to enrol. Good promotions can also have a long-term positive effect on the university itself. When both of these relationships are combined, a student satisfaction model is developed. This model is an alteration of a proposed model based on a pre-conceptual model by Jurkowitsch et al. (2006).

From the model, it is concluded that student satisfaction can be measured from students' perception on three antecedent factors; service performance, university performance and university standing. The promotion factor is significantly influenced by overall satisfaction that students have on course delivery, campus and faculty facilities, communication between students and university personnels and students' perception of the university standing.

\section{CONCLISION}

This study shows that there is a direct and indirect relationship between antecedents to student satisfaction with student satisfaction and promotion in the Higher Education Institutions (HEI). However, the model developed in this study may be improved further using an instrument more focused on the four antecedent factors to student satisfaction as well as the promotion factor. The student satisfaction model developed using SEM in this study is hoped to give a meaningful impact in measuring the student satisfaction of engineering students in HEI particularly in Malaysia and to increase efforts in endeavouring for higher level achievement leading to student satisfaction.

\section{ACKNOWLEDGEMENT}

This research is sponsored by a research grant UKM-GUP-BTT-07-25-168 from Universiti Kebangsaan Malaysia.

\section{REFERENCES}

Abdullah, M., M.R.A. Hamid, Z. Mustafa, N.R.M. Suradi and F. Idris et al., 2011. Value-Based Total Performance Excellence Measurement (VBTPEM): An overview of agenda and transformation. J. Q. Measu. Anal., 7: 67-75.

Aldrige, S. and J. Rowley, 1998. Measuring customer satisfaction in higher education. Q. Assu. Educ., 6: 197-204. DOI: $10.1108 / 09684889810242182$

Arnett, D.B., S.D. German and S.D. Hunt, 2003. The identity salience model of relationship marketing success: The case of non-profit market. J. Market., 67: 89-105. 
Babakus, E. and G.W. Boller, 1992. An empirical assessment of the SERVQUAL scale. J. Bus. Res., 24: 253-268. DOI: 10.1016/0148-2963(92)90022-4

BCCISO, 2003. Understanding Student Satisfaction. College BC and Institute Student Outcomes.

Bloemer, J. and K.D. Ruyter, 1998. On the relationship between store image, store satisfaction and store loyalty. Eur. J. Market., 32: 499-513. DOI: 10.1108/03090569810216118

Byrne, B.M., 2001. Structural Equation Modeling with AMOS: Basic Concepts, Applications and Programming. 1st Edn., Routledge, USA., ISBN: 0805841040 , pp: 352.

Cheung, G.W. and R.B. Rensvold, 2002. Evaluating goodness-of-fit indexes for testing measurement invariance. Struct. Equat. Model.: Multidisciplinary J., 9: 233-255. DOI: 10.1207/S15328007SEM0902_5

Elliot, K.M. and D. Shin, 2002. Student Satisfaction: An alternative approach to assessing this important concept. J.Higher Educ. Policy Manage., 24: 197209. DOI: $10.1080 / 1360080022000013518$

Garbarino, E. and M.S. Johnson, 1999. The different roles of satisfaction, trust and commitment in customer relationships. J. Market., 63: 70-87.

Hair, J.F. and R.E. Anderson, 2010. Multivariate Data Analysis. 7th Edn., Prentice Hall, Upper Saddle River, ISBN: 0138132631, pp: 785.

Hamid M.R.A., Z. Mustafa, N.R.M. Suradi, M. Abdullah and W.R. Ismail et al., 2010a. Valuebased total performance excellence model: An overview. J. Technol., 52: 95-104.

Hamid, M.R.A., Z. Mustafa, F. Idirs, M. Abdullah and N.R.M. Suradi 2011b. Multi-factor of cultural values: A confirmatory factor analytic approach. Q. Quantity. DOI: 10.1007/s11135-011-9532-z

Hamid, M.R.A., Z. Mustafa, F. Idris, M. Abdullah and N.R.M. Suradi, 2011a. Measuring value-based productivity: A Confirmatory Factor Analytic (CFA) approach. Int. J. Bus. Soc. Sci., 2: 85-93.

Hill, F.M., 1995. Managing service quality in higher education: The role of the student as primary consumer. Q. Assu. Educ., 3: 10-21. DOI: 10.1108/09684889510093497

Joseph, M. and B. Joseph, 1997. Service quality in education: A student perspective. Q. Assu. Educ., 5: 15-21. DOI: 10.1108/09684889710156549
Jurkowitsch, S., C. Vignali and H.R. Kaufmann, 2006. A student satisfaction model for austrian higher education providers considering aspects of marketing communications. Innovative Market., 2: 9-23.

Khozaei, F., A.S. Hassan and Z. Khozaei, 2010. Undergraduate students' satisfaction with hostel and sense of attachment to place: Case study of University Sains Malaysia. Am. J. Eng. Applied Sci., 3: 516-520. DOI: 10.3844/ajeassp.2010.516.520

Najib, U.M.N., N.A. Yusof and Z. Osman, 2011. Measuring satisfaction with student housing facilities. Am. J. Eng. Applied Sci., 4: 52-60. DOI: 10.3844/ajeassp.2011.52.60

Parasuraman, A., V.A. Zeithaml and L.L. Berry, 1988. SERVQUAL: A multiple-item scale for measuring consumer perceptions of service quality. J. Retail., 64: 12-40.

Parker, C. and B.P. Mathews, 2001. Customer Satisfaction: Contrasting academic and consumers' interpretations. Market Intell. Plann., 19: 38-44. DOI: 10.1108/02634500110363790

Venetis, K.A. and P.N. Ghauri, 2004. Service quality and customer retention: Building long-term relationships. Eur. J. Market., 38: 1577-1598. DOI: 10.1108/03090560410560254

Washburn, J.H. and S.M. Petroshius, 2004. A collaborative effort at marketing the university: Detailing a student-centered approach. J. Educ. Bus., 80: 35-40.

Wiers-Jenssen, J., B. Stensaker and J.B. Grogaard, 2002. Student Satisfaction: towards an empirical deconstruction of the concept. Q. Higher Educ., 8: 183-195. DOI: 10.1080/1353832022000004377

Wirtz, J. and J.E.G. Bateson, 1999. Consumer satisfaction with services: Integrating the environment perspective in services marketing into the traditional disconfirmation paradigm. J. Bus. Res., 44: 55-66. DOI: 10.1016/S01482963(97)00178-1

Woodruff, R.B., E.R. Cardotte and R.L. Jenkins, 1983. Modeling consumer satisfaction processes using experience-based norms. J. Market. Res., 20: 296304.

Yau O.H.M., P.R. McFetridge, R.P.M. Chow, J.S.Y. Lee and L.Y.M. Sin et al., 2000. Is relationship marketing for everyone? Eur. J. Market., 34: 11111127. DOI: $10.1108 / 03090560010342494$ 